\title{
Recent techniques used in transmission line protection: a review
}

\author{
Kola Venkataramana Babu ${ }^{1}$, Manoj Tripathy ${ }^{2}$ and Asheesh K Singh ${ }^{2}$ \\ ${ }^{1}$ Research Scholar, Department of Electrical Engineering, Motilal Nehru National Institute of Technology, Allahabad (UP), INDIA. \\ ${ }^{2}$ Department of Electrical Engineering, Motilal Nehru National Institute of Technology, Allahabad (UP), INDIA \\ Corresponding author: e-mail: kvr.babu@gmail.com, Mob.+91-9936964749
}

\begin{abstract}
This article presents a survey of the developments in digital relays for protection of transmission lines. For a modern power system, selective high speed clearance of faults on high voltage transmission lines is critical and this survey indicates the efficient and promising implementations for fault detection, classification and fault location in power transmission line protection. The work done in this area favor computerized relays, digital communication technologies and other technical developments, to avoid cascading failures and facilitate safer, secure and reliable power systems. Efforts have been made to include almost all the techniques and philosophies of transmission line protection reported in the literature up to October 2010. The focus of this article is on the most recent techniques, like artificial neural network, fuzzy logic, fuzzy-neuro, fuzzy logicwavelet based and phasor measurement unit-based concepts as well as other conventional methods used in transmission line protection.
\end{abstract}

Keywords: Artificial intelligence, Digital relay, Distance protection, Fuzzy logic, Neural network, Wavelet transform.

\section{Introduction}

Transmission lines are among the power system components with the highest fault incidence rate, since they are exposed to the environment. Line faults due to lightning, storms, vegetation fall, fog and salt spray on dirty insulators are beyond the control of man. The balanced faults in a transmission line are three phase shunt and three phases to ground circuits. Single line-to-ground, line-to-line and double line-to-ground faults are unbalanced in nature. On a transmission system the protective relaying system is incorporated to detect the abnormal signals indicating faults and isolate the faulted part from the rest of the system with minimal disturbance and equipment damage. This survey attempts to cover the various developments in digital relays for transmission line protection reported in the literature up to October 2010 and point to some of the references showing promising directions.

Rockefeller first presented the implementation of digital relaying in 1969 (Rockefeller, 1969). The advances in the very large scale integrated (VLSI) technology and software techniques led to the development of microprocessor based relays that were first offered as commercial devices in 1979 (Sachdev, 1979). Selective, high speed clearance of faults on high voltage transmission lines is critical to the stability of the highly complex, modern power system. In this respect, lot of work has been done to improve the performance of digital protective relays and in the use of intelligent techniques for analysis of faults and protective relay operations.

Distance relaying principle, due to their high speed fault clearance compared with the over current relays is a widely used protective scheme for the protection of high and extra high voltage (EHV) transmission and sub-transmission lines. A distance relay estimates the electrical distance to the fault and compares the result with a given threshold, which determines the protection zone. In terms of hardware, distance relays have evolved from electromechanical relays to static relays and to microprocessorbased (digital) relays. When a fault occurs in an electrical transmission line, the distance relays detect the faulty line and type of fault but they may under reach/over reach depending upon pre-fault loading, fault resistance and remote end in-feeds. The impedance estimated by a digital distance relay reduces with the increase in the speed at which the estimate is obtained. Hence an impedance relay with a specified reach setting cannot operate at arbitrarily high speeds (Thorp et al., 1979). The first installation of digital computer for relaying began in 1960's which made it possible to store information so that the relay engineer can control the reach characteristics of a distance relay to suit the application and develop fault location algorithms (Gilcrest et al., 1972; 
Rockefeller et al., 1972; IEEE Std.37.114-2004, 2005). Such digital fault locators calculate the reactance of a faulty line estimated from the computation of voltage and current phasors at the line terminals (Sachdev et al., 1988; Adu, 2004). But these fault location methods need some simplifying hypothesis to allow the fault distance calculation, affecting the accuracy of the results. The one terminal approach is simple and easy to implement (Takagi et al., 1982; Guobing et al., 2009; Xianyning Lin et al., 2009; Eduardo De et al., 2004) although the two-end algorithms which process signals from both terminals of the line are superior in comparison to the one-end approaches (Girgis et al., 1992).

In the 70's research was concentrated on "ultra high speed protection” based on the travelling wave. The post fault wave forms in the first one or two cycles after the occurrence of a fault contain high frequency transient wave fronts. Based on the analysis of these transient state signals the fault location can be calculated within a few milliseconds of the fault initiation. Different algorithms proposed for implementation of travelling wave distance protection are reported by Desikachar et al., (1984), ShehabEldin et al., (1988), Ancell et al., (1994), Ernesto Vazquez-Martinez, (2003), Dong et al., (2009). The "positional protection" utilizes the transit times of the high frequency fault generated transients to identify the faulted line section (Bo et al., 2000). It has been noted by most of the researchers that the travelling wave based method does not perform well for faults close to the relaying point and for faults with small fault inception angle, besides they require a very high sampling rate and their implementations are more costly than implementation of impedance techniques. As the complexity of the power network increases, the transmission line protection and control must be based on real time power system changes and it must be at high speeds to ensure that the power system will not run into transient stability problems. Several papers have considered the real time power system changes and have reported about accurate, fast faulty phase selection and fault location (Horowitz et al., 1988; Dadash Zadeh et al., 2009; Dash,1987; Wang et al., 1997; Bo, 1988; Bo et al., 2003; Eissa et al., 2001; El-Arroudi et al., 2004; Pathirana et al., 2005; Bockarjova et al., 2006; Cook, 1986; kang et al., 2009; Johns et al., 1990; Zamora et al., 1996; Gopalakrishnan et al., 2000; He et al., 2006; Parikh et al., 2007; Abdelaziz et al., 2005; Girgis et al., 1998; Samantaray, 2009; Xu et al., 2008; Samantaray et al., 2008; Salat et al., 2004; Ravikumar et al., 2008; Shrivastava et al., 2007; Sanjay Dambhare et al., 2009; Law et al., 2008).

In the late 80's synchronized measurement technology emerged as a promising prospect in achieving real time protection. With global positioning system (GPS), digital measurement at different line terminals can be performed synchronously (Crossley et al., 1998; Bo et al., 2000). They are more accurate than distance relaying algorithms which are affected with inadequate modeling of transmission lines and parameter uncertainty due to line aging, line asymmetry and environmental factors. The Phasor Measurements Units (PMU) are the most widely used synchronized measurement devices for power system applications, whose measurements are synchronized with respect to a GPS clock and PMU-based fault locators are more accurate than the method based on unsynchronized phasors (Jiang et al., 2000; Lin et al., 2002; Xu et al., 2008; Lin et al., 2004; Brahma et al., 2004). The unsynchronized approaches are cheaper, since there is no need to use GPS and are not affected by errors due to different sampling rates or phase shifts introduced by the different recording devices and transducers. Such impedance based fault location methods have been presented by Novosel et al., (1996), Izykowski et al., (2006), Dascastagne et al., (2008), having negligible fault location error if phasor and transmission line parameters are accurate. Although the use of GPS, phasor measurement units (PMUs), digital communication technologies, high precision signal transducers have facilitated accurate protection of power system over a wide area, they are subjected to software insecurity and communications latency.

There is a need for the measuring algorithms that have the ability to adapt dynamically to the system operating conditions such as changes in the system configuration, source impedances and fault resistance. Keeping this in view the trends since 90's, intelligent techniques are under investigation to increase reliability, speed and accuracy of existing digital relays based on Artificial Neural Network (ANN), Fuzzy Logic (FL), Fuzzy-Neuro and Fuzzy Logic-Wavelet based systems. These developments are discussed in section 2, 3 and 4 respectively.

\section{Artificial Neural Network Approach}

The reach accuracy of an electromechanical, static or a microprocessor based distance relay is affected by different fault conditions and network configuration changes. So ANN techniques are under investigation over the past 15-20 years, which can adapt dynamically to the system operating conditions at a high speed. The ability of ANN to learn by training any complex input/output mapping and recognize the noisy patterns (those with desired segments missing and/or undesired segments added) gives them the powerful property of pattern recognition and classification (Haykin, 1994). ANNs can solve the overreach and the under reach problems which are very common in the conventional distance relay design. ANN utilizes samples of currents and voltages directly as inputs without computation of phasors and related symmetrical components. Various kinds of neural network such as multi-layer perceptron (MLP), recurrent, radial basis function (RBF), probabilistic neural network etc. are being applied for fault classification and fault location. These are designed by different training algorithms like back propagation, orthogonal least square, extended kalman filter etc.. The use of ANNs can extend the first zone of distance relays and enhance system security (Coury et al., 1998). For selecting the appropriate network configurations, the performance criteria are fault tolerance, minimal response time and generalization capabilities. ANN approach has been used to improve some of the standard functions used in protection of transmission lines. They have been related to fault direction discrimination (Sidhu et al., 1995; Sidhu et al., 2004), fault detection and classification (Dalstain et al., 1995; Kezunovic et al., 1996; Sanaye-Pasand et al., 2006; Jain et al., 2006; Coury et al., 2002), distance protection (khaparde et al., 1991; Coury et al., 1998; Cho et al., 1999), improvements in fault distance 
computation (Bouthiba, 2004; Zahra et al., 2000; Chen et al., 2000; Purushothama et al., 2001; Tawfik et al., 2001; Ekici et al., 2009), protection of series compensated lines (Novosel et al., 1996), adaptive distance protection(Khaparde et al., 1996; Jongepier et al., 1997; Bhalja et al., 2007; Aggarwal et al., 1999) and adaptive reclosing (aggarwal et al., 1994).

To make the ANN responsive to time varying voltage and current waveforms different types of recurrent networks were considered that allow the hidden units of the network to see their own previous output, so that the subsequent behavior can be shaped by previous response. Such an Elman recurrent network designed to act as the fault direction detection module of a transmission line is proposed by Sanaye-Pasand et al., (1998), Sanaye-Pasand et al., (1999). Inside these ANNs the operations that take place are not clearly defined and hence they are not considered highly reliable. Further development is the concept of supervised clustering to reduce the number of iterations in the learning process of multi layer feed forward networks (Kezunovic et al., 1995). A neural network simulator is developed by Venkatesan et al., (2001), to identify the optimum ANN structure required for training the data and to implement the ANN in hardware. Still the problem with ANN's is that no exact rule exists for the choice to the number of hidden layers and neurons per hidden layer. So it is uncertain whether the ANN based relay gives the optimum output, to maintain the integrity of the boundaries of the relay characteristics. A high speed distance relaying scheme based on radial basis function neural network (RBFNN) is proposed by Pradhan et al., (2001), due to its ability to distinguish faults with data falling outside the training pattern. A sequential procedure is presented by Dash et al., (2001), for distance protection using a minimal radial basis function neural network (MRBFNN), to determine the optimum number of neurons in the hidden layer without resorting to trial and error. The use of separate ANNs, for faults involving earth and not involving earth has proved to be convenient way of classification of transmission faults based on RBF neural networks by Mahanty et al., (2004). For simple and reduced architecture and better learning capability a modular neural network, is proposed by Lahiri et al., (2005), Pradhan et al., (2001) to discriminate the direction of faults for transmission line protection. Such a network considers corresponding phase/ground voltage and current information as input and thereby the redundant inputs in conventional approaches are eliminated. The existing ANN based solutions easily converge on local minima whenever input patterns with large dimensionality are present and when designed for specific applications, are prohibitively expensive or infeasible for real time implementations. It is observed that the ANN based distance relays need much larger training sets and hence the training of these networks is time consuming and further research work shall produce a hardware realization with proper modification in the learning methodology and preprocessing of input data that would improve the learning rate performance, efficiency and the reliability many folds. Presently research efforts are in the direction of evolutionary computational techniques such as genetic algorithms (GA) for determining the neural network weights and thereby avoid training of ANN.

\section{Fuzzy Logic and Combined Neural Network/Fuzzy Logic Approach}

Zadeh introduced the concept of fuzzy set theory in 1965 for dealing with uncertain and ambiguous properties of events (Zadeh, 1965). It was introduced in power system networks to solve uncertainty problems that arise due to the continuously varying power system parameters. The key benefit of fuzzy logic is that its knowledge representation is explicit, using simple "IFTHEN" relations. The fuzzy set theory is used for fault type identification on a transmission line by Ferrero et al., (1995), Das et al., (2005), without any computationally expensive training of ANN or expert domain knowledge. These algorithms are fairly accurate only under certain assumptions of fault distance, prefault power flow, fault resistance and line length. Fuzzy sets are good at various aspects of uncertain knowledge representation, while neural networks are efficient structures capable of learning from examples. Neural network has the shortcoming of implicit knowledge representation, whereas fuzzy logic systems (FLS) are subjective and heuristic. In a fuzzy neural network (FNN), a neural network is used to implement a fuzzy rule-based system from input/output data to enhance the learning capabilities, plus knowledge illustration of fuzzy logic system. Wang et al., (1998), proposed three different neuro-fuzzy networks in series to classify the fault in transmission line protection using both designer's experiences and sample data sets. A distance relaying scheme based on FNN is proposed by Dash et al., (2000) in which the fuzzy view point is utilized to simply the model, but the FNN's calculate the fault distance within $80 \%$ of the line. A new concept of transmission line fault classification algorithm using a self-organized neural network based on adaptive resonance theory (ART) with fuzzy K-nearest neighbor (K-NN) decision rule is proposed by Vasilic et al., (2005), to improve algorithm selectivity for a variety of real events not necessarily anticipated during training. An algorithm is developed by Yeo et al., (2003), using the adaptive network-based fuzzy inference system (ANFIS) for fault detection and classification in transmission lines based on root mean square value of phase current and zero sequence current, under a wide variety of system and fault conditions including contingencies such as high impedance faults.

In fuzzy logic based protection system, accuracy cannot be guaranteed for wide variations in system conditions. So consequently a more dependable and secure relaying algorithm during real time implementation is needed for classifying the faults under a variety of time-varying network configurations. The fuzzy-neuro approaches are sensitive to system frequency changes and require large training sets and a large number of neurons affecting their accuracy and speed in protecting large power networks. 


\section{Wavelet Approach}

The fundamental frequency components of the post fault voltages and currents need to be extracted as quickly and accurately as possible for the quick response of a digital distance relay. Wavelet approach is one of the new tools in this direction which is useful for power system transient analysis, since the conventional signal processing techniques have the inherent disadvantages of long discrimination time, errors in impedance calculations and misclassifications (during CT saturation and in presence of fault resistance) (Liang et al., 2004; Bhowmik et al., 2009; Magnago et al., 1998). Wavelet transform (WT) has the ability to perform local analysis of relaying signals without losing the time-frequency information. WT in conjunction with AI/Fuzzy/Expert system/SVM based techniques have the advantage of fast response and increased accuracy in fault type and location identification. A preprocessing module based on discrete wavelet transform (DWTs) considerably simplifies the input signal, reducing the volume of input data fed into an ANN that classifies the fault events (Martin et al., 2003). A solution for protection of parallel transmission lines by decomposing fault current signals using WT and by comparing the magnitudes of line currents in the corresponding phases is presented by Osman et al., (2004).

The ability of wavelets to decompose the signal into different frequency bands using multi resolution analysis (MRA) allows detecting and classifying faults as well as extracting the voltage and current fundamental phasors needed to calculate the impedance to the fault point in distance protection (Osman et al., 2004) and with filtering algorithms proposed by Kleber M.Silva et al., (2010), fast relay operating times are obtained. Discrete wavelet transform based MRA is used for feature extraction by Samantaray et al., (2007) and the features extracted from fault current signals are used to train and test the support vector machine (SVM) for fault classification and the fault location from the relaying point is computed by RBFNN. A solution to the complexities of the protection of series compensated transmission lines is proposed by Parikh et al., (2008), which is a combination of wavelet-SVM technique for fault zone identification. In a Fuzzy-logic-wavelet based technique the wavelet transform of current signal provides hidden information of a fault situation to FLS, to classify the fault and these are reported in (Youssef et al., 2004; Reddy et al., 2006; Reddy et al., 2007; Pradhan et al., 2004). These fuzzy procedures solve the problem with simple computational procedures rather than using more complex algorithms in the deterministic way. Some more improved solutions to detect the faults precisely with wavelet transform based digital protection for transmission lines are proposed by Zhang et al., (2007), Valsan et al., (2009), Da silva et al., (2010). The combined techniques of WT with ANN and WT with Fuzzy Logic depend on huge samples and trainings for knowledge representation, leading to an excessively complicated job. Wavelet singular entropy (WSE) technique which indicates the uncertainty of the energy distribution in the time-frequency domain is used to extract features from fault transients for the fault diagnosis in EHV transmission lines (Zhengyou He et al., 2010).The capabilities of wavelets are affected owing to the existence of noises riding high on the signal and the problem lies in identification of the most suitable wavelet family that is more approximate for use in estimating fault location. Most of the wavelet based techniques employ multi-level wavelet decomposition, which requires multi-level filtering followed by complex computations. Wavelet transform will emerge as a powerful tool in transmission line protection provided further work is done in reducing the algorithm complexity, computational burden and response time.

\section{Conclusions}

A survey of transmission line protection is done through this article. Since the implementation of digital relaying, a lot of work has been done to improve the performance of digital protective relays, but in the context of reformation in the power industry and operation of transmission lines close to the stability limits, new tools and algorithms are needed to maintain system reliability and security within an acceptable level. The ANN, fuzzy logic, genetic algorithm, SVM and wavelet based techniques have been quite successful but are not adequate for the present time varying network configurations, power system operating conditions and events. Therefore, it seems that there is a significant scope of research in AI techniques which can simplify the complex nonlinear systems, realize the cost effective hardware with proper modification in the learning methodology and preprocessing of input data and which are computationally much simpler. Also development of reliable software and communication system will pave the way for better relaying and fault location performance using multi terminal synchronized phasor measurement based on GPS. This article is an effort to present the most comprehensive set of references on the subject of recent techniques in transmission line protection.

\section{References}

Abdelaziz A.Y., Ibrahim A.M., Mansour M.M. and Talaat H.E., 2005. Modern approaches for protection of series compensated transmission lines, Electrical Power Systems Research, vol.75, no.1, pp. 85-98.

Adu T., 2004. A new transmission line fault locating system, IEEE Trans. Power Delivery, vol.16, No.4, pp. 498-503.

Aggarwal R.K., Johns A.T., Song Y.H., Dunn R.W. and Fitton D.S., 1994. Neural network based adaptive single-pole autoreclosure technique for ehv transmission systems, IEE Proc.-C, vol. 141(2), pp.155-160.

Aggarwal R.K., Xuan Q.Y, Johns A.T. and Bennett A., 1999. High adaptive distance protection of double-circuit lines using Artificial Neural Networks, IEEE Trans. Power Delivery, vol. 14, no.4, pp. 1250-1256. 
Ancell G.B. and Pahalawaththa N.C., 1994. Maximum likelihood estimation of fault location on transmission lines using travelling waves, IEEE Trans. Power Delivery, vol.9 No.2 pp.680-688.

Bhalja B.R. and Maheswari R. P., 2007. High resistance faults on two terminal parallel transmission line: Analysis, simulation studies, and an adaptive distance relaying scheme, IEEE Trans. Power Delivery, vol.22, no.2, pp. 801-812.

Bhowmik P.S., Purkait P. and Bhattacharya K., 2009. A novel wavelet transform aided neural network based transmission line fault analysis method, Electrical Power and Energy Systems, vol.31, no.5, pp.213-219.

Bo Z.Q., 1998. A new non-communication protection technique for transmission lines, IEEE Trans. Power Del., vol.13, no.4, pp.1073-1077.

Bo Z.Q., Dong X.Z., Ben R.J,Caunce, and Robin Millar, 2003. Adaptive Non-communication Protection of Double-circuit line systems, IEEE Trans. Power Del., vol.18, no.1, pp.43-49.

Bo Z.Q., Redfern M.A., and Weller G.C., 2000. Positional protection of transmission line using fault generated high frequency transient signals, IEEE Trans. Power .Del., vol. 15, no.3, pp. 888-894.

Bo Z.Q., Weller G., Lomas T., and Redfern M.A., 2000. Positional protection of transmission systems using global positioning system, IEEE Trans. Power Delivery, vol.15, No.4, pp. 1163-1167.

Bockarjova M., Sauhats A. and Anderson G., 2006. Statistical algorithm for power transmission lines distance protection, in proc.9th int. conf. on probabilistic methods applied to power systems, KTH, Stockholm, Sweden- June 11-15.

Bouthiba T., 2004. Fault location in EHV Transmission lines using artificial neural networks, International Journal of Applied Mathematics and Computer Science, vol.14, no.1, pp 69-78.

Brahma S.M. and Girgis A.A., 2004. Fault location on a transmission line using synchronized voltage measurements, IEEE Trans. Power Delivery, vol.19, No.4, pp.1619-1622.

Chen Z. and Maun J.C., 2000. Artificial neural network approach to single-ended fault locator for transmission lines, IEEE Trans. On Power Systems, vol.15, no.1, pp.170-175.

Cho K.R., Kang Y.C., Kim S.S., Park J.K., Kang S.H. and Kim K.H., 1999. An ANN based approach to improve the speed of a differential equation based distance relaying algorithm. IEEE Trans. Power Delivery, vol. 14, no.2, pp. 349-357.

Cook V., 1986. Fundamental aspects of fault location algorithms used in distance protection, Proc, IEE, vol.137, no.6, pp. 359368.

Coury D. V. and Jorge D.C., 1998. Artificial neural network approach to distance protection of transmission lines, IEEE Trans. Power Delivery, vol. 13, no. 1, pp. 102-108.

Coury D.V. and Oleskovicz M., 1998. Multi-layer neural networks applied to distance relaying, Electric Power \& Energy Systems, vol. 20, no. 8, pp. 539-542.

Coury D.V., Oleskovicz M. and Aggarwal R.K., 2002. An ANN routine for fault detection, classification and location in transmission lines, Electrical Power Components and Systems, vol.30, no.11, pp.1137-1149.

Crossley P.A. and Southern E., 1998. The impact of the global positioning system (GPS) on protection and control, in proc.11 ${ }^{\text {th }}$ int. conf. power system protection, Bled, Slovenia, pp.1-5.

Da Silva M., Coury D.V., Oleskovicz M., and Segatto E.C., 2010. Combined solution for fault location in three terminal lines based on wavelet transforms, IET Gener. Transm. Distrib., vol.4, no.1, pp.94-103.

Dadash Zadeh M.R., Sidhu T.S., and Klimek A., 2009. Field-Programmable analog array based distance relay, IEEE Trans. Power Delivery, vol.24, No.3, pp.1063-1071.

Dalstain T., and Kulicke B., 1995. Neural network-approach to fault classification for high speed protective relaying, IEEE Trans. Power Delivery, vol. 10, no. 2, pp. 1002-1011.

Das B. and Vittal Reddy J., 2005. Fuzzy-Logic-Based fault classification scheme for digital distance protection, IEEE Trans. Power Delivery, vol.20, no.2, pp.609-616.

Dascastagne A.L., Filho S.N., zurn H.H, and Seara R., 2008. An iterative two-terminal fault-location method based on unsynchronized phasors, IEEE Trans. Power Delivery, vol.23, No.4, pp.2318-2329.

Dash P.K., 1987. Recursive functional expansion technique for computer-based impedance and differential protection, Electric power and Energy systems, vol.9, no.4, pp.225-232.

Dash P.K., Pradhan A.K. and Panda G., 2001. Application of minimal radial basis function neural network to distance protection, IEEE Trans. Power Delivery, vol. 16, no.1, pp.68-74.

Dash P.K., Pradhan A.K., and Panda G., 2000. A novel fuzzy neural network based distance relaying scheme, IEEE Trans. Power Delivery, vol.15, no.3, pp. 902-907.

Desikachar K.V. and Singh L.P., 1984. Digital Travelling-Wave Protection of transmission lines, Electric Power Systems Research, vol.7, no.1, pp. 19-28.

Dong X., Kong W. and Cui T. 2009. Fault classification and faulted-phase selection based on the initial current travelling wave, IEEE Trans. Power Delivery, vol.24, No.2, pp.552-559.

Eduardo De C., Pereira M. and Zanetta L. C., 2004. Fault location in transmission lines using one terminal post fault voltage data, IEEE Trans. Power Delivery, vol.19, No.2, pp 570-575.

Eissa M.M. and Masoud M.,2001. A novel digital distance relaying technique for transmission line protection, IEEE Trans. Power Del., vol.16, no.3, pp.380-384. 
Ekici S., Yildirim S. and Poyraz M., 2009. A transmission line fault locator based on elman recurrent networks, Applied soft computing, vol.9, pp.341-347.

El-Arroudi K., Joos G., Mcgillis D. T., and Brearley R., 2004. The performance specification of transmission line protection using a knowledge-based approach, IEEE Trans Power Del., vol.19, no.3, pp.1049-1055.

Ernesto Vazquez-Martinez, 2003. A Travelling wave distance protection using principle component analysis, International Journal of Electric Power and Energy Systems, vol.25, no.6, pp. 471-479.

Ferrero A., Sangiovanni S. and Zappitelli E., 1995. A fuzzy-set approach to fault-type identification in digital relaying, IEEE Trans. Power Delivery, vol.10, No.1, pp.169-175.

Gilcrest G.B., Rockefeller G.D., and Udren E.A., 1972. High speed distance relaying using a digital computer. Part I system description, IEEE Trans. Power Apparatus and Systems, vol.PAS-91, no.3, pp. 1235-1243.

Girgis A.A., Hart D.G. and Peterson W.L., 1992. Fault location in transmission lines using two and three terminal lines, IEEE Trans. Power Delivery, vol.7, no.1, pp. 98-107.

Girgis A.A., Sallam A.A. and Karim El-Din A., 1998. An adaptive protection scheme for advanced series compensated (ASC) transmission lines, IEEE Trans. Power Del. vol.13, no.2, pp. 414-420.

Gopalakrishnan A., Kezunovic M., McKenna S.M. and Hamai D.H.,2000. Fault location using the distributed parameter transmission line model, IEEE Trans. Power Delivery, vol.15, No.4, pp. 1169-1174.

Guobing S., Suonan Jiale and Ge Yaozhong, 2009. An accurate fault location algorithm for parallel transmission lines using one terminal data, Electrical Power and Energy systems, vol.31, no.2-3, pp.124-129.

Haykin S., 1994 Neural Networks, IEEE Press, New York.

He B., Li Y. and Bo Z.Q., 2006. An adaptive distance relay based on transient error estimation of CVT, IEEE Trans .Power Del., vol.21, no.4, pp.1856-1861.

Horowitz S.H., Phadke A.G., and Thorp J.S., 1988. Adaptive transmission system relaying, IEEE Trans. Power Del.,vol.3, no.4, pp.1436-1445.

IEEE Guide for Determining Fault Location on AC Transmission and Distribution lines, 2005. IEEE Std. 37.114-2004.

Izykowski J., Molag R., Rosolowski E. and Saha M.M.,2006. Accurate location of faults on power transmission lines with use of two-end unsynchronized measurements, IEEE Trans. Power Delivery, vol.21, No.2, pp.627-633.

Jain A., Kale V.S. and Thoke A.S., 2006. Application of artificial neural networks to transmission line faulty phase selection and fault distance location, proceedings of the IASTED international conference "Energy and Power system," Chiang Mai, Thailand, pp.262-267, Mar. 29-31.

Jiang J.A., Lin Y.H., Yang J.Z., Too T.M. and Liu C.W., 2000. An adaptive PMU based fault detection/location technique for transmission lines part-II; PMU implementation and performance evaluation, IEEE Trans.Power Delivery, vol.15, No.4, pp.1136-1146.

Jiang J.A., Yang J.Z., Lin Y.H., Liu C.W., and Ma J.C., 2000. An adaptive PMU based fault detection/location technique for transmission lines part-I; Theory and algorithms, IEEE Trans. Power Delivery, vol.15, No.2,pp.486-493.

Johns.A.T. and Jamali.S., 1990. Accurate fault location technique for power transmission lines, IEE Proc., vol. C137, no.6, pp. 395-402.

Jongepier A.G., Kema B.V. and Van der Sluls L., 1997. High adaptive distance protection of double-circuit lines using artificial neural networks, IEEE Trans. Power Delivery, vol. 12, no.1,pp. 97-105.

Kang S.H., Ahn Y.J., Kang Y.C. and Nam S.R., 2009. A fault location algorithm based on circuit analysis for untransposed parallel transmission lines, IEEE Trans. Power Delivery, vol.24, No.4, pp.1850-1856.

Kezunovic M. and Rikalo I., 1996. Detect and Classify faults using neural nets, IEEE Computer Applications in Power, pp. 42-47.

Kezunovic M., Rikalo I. and Sobajic D.J., 1995. High-speed fault detection and classification with neural nets, Electric Power Systems Research, vol. 34, no.2,pp109-116.

Khaparde S.A., Kale P.B. and Agarwal S.H., 1991. Applications of artificial neural networks in protective relaying of transmission lines, Proc.Ist Int.Forum of Neural Networks to Power Systems, Seattle, WA, USA, pp.122-126.

Khaparde S.A., Warke N. and Agarwal S.H., 1996. An adaptive approach in distance protection using an artificial neural network, Electric Power Systems Research, vol. 37, no. 1, pp. 39-46.

Kleber M.Silva, Washington L.A.Neves and Benemar A.Souza, 2010. Distance protection using a wavelet-based filtering algorithm, Elecrical Power Systems Research, vol.80, no.1, pp. 84-90.

Lahiri U., Pradhan A.K., and Mukhopadhyaya S., 2005. Modular neural network-based directional relay for transmission line protection, IEEE Trans. Power Delivery, vol.20, no.4, pp. 2154-2155.

Law C.T., Bhattarai K., and Yu D.C., 2008. Fiber-optics-based fault detection in power systems, IEEE Trans. Power Delivery, vol.23, No.3,pp.1271-1279.

Liang F. and Jeyasurya B., 2004. Transmission line distance protection using wavelet transform algorithm, IEEE Trans. Power Delivery, vol.19, no.2, pp. 545-553.

Lin Y.H., Liu C.W., and Chen C.S., 2004. A new PMU-based fault detection/location technique for transmission lines with consideration of arcing fault discrimination---part I: Theory and algorithms, IEEE Trans. Power Delivery, vol.19, No.4, pp.1587-1593. 
Lin Y.H., Liu C.W., and Yu C.S., 2002. A new fault locator for three-terminal transmission lines---using two-terminal synchronized voltage and current phasors, IEEE Trans. Power Delivery, vol.17, No.2, pp.452-459.

Magnago F.H. and Abur A., 1998. Fault location using wavelets, IEEE Trans. Power Delivery, vol.13, no.4, pp. 1475-1480.

Mahanty R.N. and Das Gupta P.B., 2004. Application of RBF neural network to fault classification and location in transmission lines. IEE Proc.-Transm. Distrib., vol.151, no.2, pp.201-212.

Martin F. and Aguado J.A., 2003. Wavelet-based ANN approach for transmission line protection, IEEE Trans. Power Delivery, vol.18, no.4, pp.1572-1574.

Novosel D., Bachmann B., Hart D., Yihu and Saha M. M., 1996. Algorithms for locating faults on series compensated lines using neural network and deterministic methods, IEEE Trans. Power Delivery, vol.11, no.4, pp.1728-1736.

Novosel D., Hart D.G., Udren E., Garitty J., 1996. Unsynchronized two-terminal fault location estimation, IEEE Trans. Power Delivery, vol.11, No.1,pp.130-138.

Osman A.H. and Malik O.P., 2004. Protection of parallel transmission lines using wavelet transform, IEEE Trans. Power Delivery, vol.19, no.1, pp.49-55.

Osman A.H. and Malik O.P., 2004. Transmission line distance protection based on wavelet transform, IEEE Trans. Power Delivery, vol.19, no.2, pp. 515-523.

Parikh U.B., Bhalja B.R. jr., Maheshwari R.P., Das B., 2007. Decision tree based fault classification scheme for protection of series compensated transmission lines, International journal of emerging electric power systems, vol.8, no. 6, pp. 1-12.

Parikh U.B., Das B., and Maheswari R.P., 2008. Combined wavelet-SVM technique for fault zone detection in a series compensated transmission line, IEEE Trans. Power Delivery, vol.23, no.4, pp. 1789-1794.

Pathirana V. and McLaren P.G., 2005. A hybrid algorithm for high speed transmission line protection, IEEE Trans. Power Del., vol.20, no.4, pp. 2422-2428.

Pradhan A.K., Dash P.K. and Panda G., 2001. A fast and accurate distance relaying scheme using an efficient radial basis function neural network, Electric Power Systems Research, vol.60, no.1, pp. 1-8.

Pradhan A.K., Mohanty S.R. and Routray A. 2001. Neural fault classifier for transmission line protection - a modular approach, in proc. Power Engineering Society summer meeting, IEEE, vol.1, pp.127-132.

Pradhan A.K., Routray A., Pati S., and Pradhan D.K., 2004. Wavelet fuzzy combined approach for fault classification of a seriescompensated transmission line, IEEE Trans. Power Delivery, vol.19, no.4, pp. 1612-1618.

Purushothama G.K., Narendranath A.V., Thukaram D., Parthasarathy K., 2001. ANN applications in fault locators, Electrical power and energy systems, vol.23, no.6, pp.491-506.

Ravikumar B., Thukaram D. and Kincha H.P., 2008. Application of support vector machines for fault diagnosis in power transmission system, IET Gener. Transm. Distrib., vol.2, no.1, pp.119-130.

Reddy M.J. and Mohanta D. K., 2006. A comparative study of artificial neural network (ANN) and fuzzy information system (FIS) approach for digital relaying of transmission line faults, AIML journal, vol.6, no.4, pp. 1-7.

Reddy M.J. and Mohanta D.K., 2007. A wavelet-fuzzy combined approach for classification and location of transmission line faults, Electrical Power and Energy Systems, vol.29, no.1, pp.669-678.

Rockefeller G.D. and Udren E.A.,1972. High speed distance relaying using a digital computer part II, IEEE Trans. Power Apparatus and Systems, vol.PAS-91, no.3.pp.1244-1256.

Rockefeller G.D., 1969. Fault protection with a digital computer, IEEE Trans. Power App. and Syst., vol. 88, no.4, pp.438-464.

Sachdev M.S.and Agarwal R., 1988. A technique for estimating transmission line fault locations from digital impedance relay measurements, IEEE Trans. Power Delivery, vol.3, no.1, pp 121-129.

Sachdev M.S., (Coordinator), 1979. Computer relaying, IEEE Tutorial course text pub. 79EH0148-7-PWR.

Salat R. and Osowski S., 2004. Accurate fault location in the power transmission line using support vector machine approach, IEEE Trans. Power Delivery, vol.19, No.2., pp.979-986.

Samantaray S.R. and Dash P.K., 2008. Transmission line distance relaying using machine intelligence technique, IET Gener. Transm. Distrib., vol.2, no.1, pp.53-61.

Samantaray S.R., Dash P.K. and Panda G., 2007. Distance relaying for transmission line using support vector machine and radial basis function neural network, Electrical power and energy systems, vol. 29, no.7, pp.551-556.

Samantaray S.R., 2009. Decision tree-based fault zone identification and fault classification in flexible AC transmission-based transmission line, IET Gener. Transm. Distrib, vol. 3, Iss.5, pp. 425-436.

Sanaye-Pasand M. and Kharashadi-Zadeh H.,2006. An extended ANN-based high speed accurate distance protection algorithm, Electrical Power and Energy Systems, vol.28, no.6, pp. 387-395.

Sanaye-Pasand M. and Malik O.P., 1998. High speed transmission system directional protection using an elman network, IEEE Trans. Power Delivery, vol, 13, no.4, pp.1040-1045.

Sanaye-Pasand M. and Malik O.P., 1999. High speed transmission system directional protection evaluation using field data, IEEE Trans. Power Delivary, vol, 14 no.3, pp. 851-856.

Sanjay Dambhare, Soman S.A. and Chandorkar M.C., 2009. Adaptive current differential protection schemes for transmission-line protection, IEEE Trans. Power Delivery, vol.24, No.4, pp.1832-1841. 
Shehab-Eldin E.H. and Mclaren P.G., 1988. Travelling wave distance protection- problem areas and solutions, IEEE Trans. Power delivery, vol.3, no.3, pp. 894-902.

Shrivastava K., Vishwakarma D.N., 2007. Microcontroller-based numerical quadrilateral relay for the transmission line protection, Electrical Power Components and Systems, vol.35, no.12, pp.1301-1315.

Sidhu T.S., Mital L. and Sachdev M.S., 2004. A comprehensive analysis of an artificial neural-network-based fault direction discriminator, IEEE Trans. Power Delivery, vol.19, no.3, pp.1042-1048.

Sidhu T.S., Singh H. and Sachdev M.S., 1995. Design, implementation and testing of an artificial neural network based fault direction discriminator for protecting transmission lines, IEEE Trans. Power Delivery, vol. 10, no. 2, pp. 697-706.

Takagi T., Yamakoshi Y., Yamaura Y., Kondow R., and Matsushima T., 1982. Development of a new type fault locator using the one terminal voltage and current data, IEEE Trans. Power Apparatus and systems, vol.101, no.8, pp.2892-2898.

Tawfik M.M. and Marcos M.M., 2001. ANN-based techniques for estimating fault location on transmission lines using prony method, IEEE Trans. Power Delivery, vol.16, no.2, pp. 219-224.

Thorp J.S., Phadke A.G, Horowitz S.H. and Bechler J.E., 1979. Limits to impedance relaying, IEEE Trans. Power App. Systems, vol.PAS-98, no.1, pp.246-256.

Vasilic S. and Kezunovic M., 2005. Fuzzy ART neural network algorithm for classifying the power system faults, IEEE Trans. Power Delivery, vol.20, no.2, pp.1306-1314.

Venkatesan R. and Balamurugan B., 2001. A real-time hardware fault detector using an artificial neural network for distance protection, IEEE Trans. Power Delivery, vol.16, no.1, pp.75-82.

Valsan, Swarup K.S., 2009. Wavelet transform based digital protection for transmission lines, Electrical Power and Energy Systems, vol.31, no.7-8, pp. 379-388.

Wang F. and Tang J., 1997. Modeling of a transmission line protection relaying scheme using petri nets, IEEE Trans. Power Del., vol.12, no.3, pp. 1055-1063.

Wang H. and Keerthipala W.W.L., 1998. Fuzzy- Neuro approach to fault classification for transmission line protection, IEEE Trans. Power Delivery, vol.13, no.4, pp. 1093-1104.

Xiangning Lin, Hanli weng and Bin Wang, 2009. A generalized method to improve the location accuracy of the single-ended sampled data and lumped parameter model based fault locators, Electrical power and energy systems, vol.31, no.5, pp 201-205.

Xu Z.Y., Huang S.F., Li Ran. Liu J.F., Qin Y.L., Yang Q.X. and He J.L., 2008. A distance protection relay for a 1000-kV UHV transmission line, IEEE Trans. Power Del., vol.23, no.4, pp. 1795-1804.

Xu Z.Y., Jiao S.H., Ran L., and Du Z.Q., 2008. An online fault-locating scheme for EHV/UHV transmission lines, IET Gener. Transm. Distrib., vol.2, no.6, pp.789-799.

Yeo S.M., Kim C.H., Hong K.S., Lim Y.B., Aggarwal R.K., Johns A.T., and Choi M.S., 2003. A novel algorithm for fault classification in transmission lines using a combined adaptive network and fuzzy inference system, Electrical Power and Energy Systems, vol.25, no.9, pp.747-758.

Youssef O.A.S., 2004. Combined fuzzy-logic wavelet-based fault classification technique for power system relaying, IEEE Trans. Power Delivery, vol.19, No.2, pp.582-589.

Zadeh L.A., 1965. Fuzzy sets, Inform. Control, vol.8, pp. 338-353.

Zahra F., Jayasurya B. and Quaicoe J.E., 2000. High-speed transmission relaying using artificial neural networks, Electric Power Systems Research, vol. 53, no.3, pp. 173-179.

Zamora I., Minambres J.F., Mazon A.J., Alvarez-Isasi R., and Lazaro J., 1996. Fault location on two-terminal transmission lines based on voltages, IEE Proc. - Gener. Transm. Distrib., vol.143, No.1, pp.1-6.

Zhang N. and Kezunovic M., 2007. Transmission line boundary protection using wavelet transform and neural network, IEEE Trans. Power Delivery, vol.22, no.2, pp. 859-869.

Zhengyou He, Ling Fu, Sheng Lin and Zhiqian Bo, 2010. Fault detection and classification in EHV transmission line based on wavelet singular entropy, IEEE Trans. Power Delivery, vol.25, no.4, pp. 2156-2163.

\section{Biographical notes}

Kola Venkataramana Babu is currently pursuing the Ph.D. degree in Electrical Engineering at MNNIT, Allahabad, India. His research interests are in electrical power system Protection, PMU based and artificial intelligence based relays.

Manoj Tripathy was born in Gorakhapur India. He received the Ph.D. degree from Indian Institute of Technology Roorkee, Roorkee, India, in 2008. He is presently Assistant Professor with the Department of Electrical Engineering, MNNIT. His research interests are in the area of Power System Protection, Digital/Numerical Relays, and Artificial Intelligence Based Relays.

Asheesh K Singh was born on July 18, 1971 in Kanpur India. He received the Ph.D. degree from Indian Institute of Technology Roorkee, Roorkee, India, in 2006. He is presently Associate Professor with the Department of Electrical Engineering, MNNIT Allahabad, India. His research interests are in the area of Power Quality, Power system Harmonics, Voltage unbalance, Energy efficiency and Energy audit.

Received February, 2011

Accepted March, 2011

Final acceptance in revised from April, 2011 